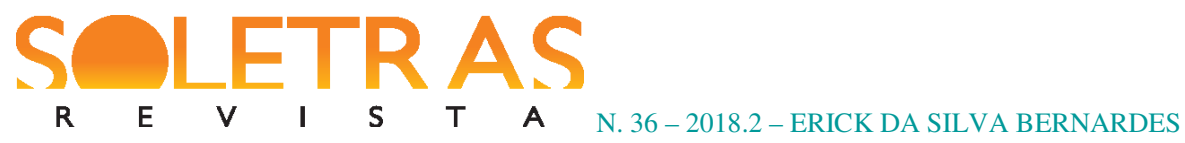

\title{
Entrevista con Alberto Guerra Naranjo ${ }^{1}$
}

Soletras: ¿Para el público brasileño, aún poco familiarizado con su obra, como el ciudadano y el escritor Alberto Guerra Naranjo quisiera ser presentado?

Alberto Guerra Naranjo, escritor de ficciones.

Soletras: ¿Cómo analiza el panorama de la literatura cubana contemporánea? ¿Cómo usted define su poética en ese panorama de hoy, con relación a Cuba y las demás literaturas latinoamericanas?

Cuba contiene en sí una productiva y poderosa zona literaria en la actualidad. Coexisten varias generaciones de escritores intercambiando textos y visiones que van desde los escritores que tienen ochenta y tantos años hasta los que andan escribiendo buenos textos y solo cuentan con una veintena de años. Creo que es un panorama muy rico y desconocido para el lector de otras regiones del mundo y de Latinoamérica y eso es lo lamentable, pero a través de las redes sociales y de proyectos como el de ustedes el desconocimiento será menor en la medida en que nos empeñemos en mostrar nuestras literaturas e intercambiarlas como debe ser.

Soletras: Usted es un ficcionista. ¿Ha acompañado las demás producciones, en la lírica, en el drama en su país?

El asunto es expresarse, pues se vive una sola vez y hay que aprovechar los tiempos y las energías creadoras. A mí me interesa contar historias en cualquier formato, el asunto es contarlas, que lleguen al otro que las está esperando o que se encuentra con ellas aun sin esperarlas. Escribo sobre mi país sin complejos ni culpas, porque escribiendo sobre las pequeñas historias de mi Pueblo, que son las que conozco, me pongo en planes universales al tener en cuenta que el universo anda en el corazón de cada individuo, de cada Pueblo, de cada ciudad, de cada país, y del planeta.

Soletras: El cine entra de forma bastante contundente en su vida. ¿Cómo se ha dado esa relación de la literatura con las demás artes, en su obra y en Cuba?

\footnotetext{
1 Alberto Guerra Naranjo (Havana, 30 de dezembro de 1961 -) é escritor, licenciado em História e Ciências Sociais. Um dos mais importantes escritores cubanos de hoje, é roteirista, autor do romance La soledad del tiempo (2009) e dos livros de contos Disparos em aula, Aporias de la feria, Blasfemia del escriba, dentre outras obras. Em 2015, teve alguns de seus contos publicados no Brasil, em Com tato cubano, pela Kitabu Editora.

${ }^{2}$ Mestrando em Estudos Literários pelo Programa de Pós-Graduação em Letras e Linguística da FFP/UERJ. Ficcionista e ensaísta. Publicou em 2018 a coletânea de contos Panapaná, pela Editora Autografia.
}

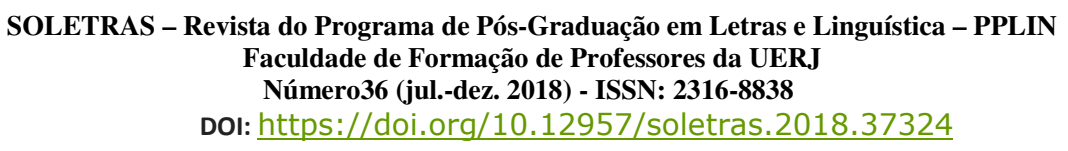




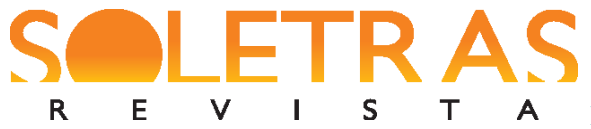

Como escribo historias en cualquier formato, el guion de cine es uno de ellos y muy abarcador en cuanto al público que consume audiovisuales, que es mayor que el público que lee libros de cuentos y de novelas. Soy profesor de Escritura de Guiones, he laborado por años en la universidad impartiendo esta materia y he llegado a la simple conclusión de que el asunto es expresarse lo mejor posible en cualquier ámbito humano donde el arte signifique.

Soletras: ¿Cómo es la situación de la lectura y del libro en Cuba, con relación al mercado, al público consumidor, a la internacionalización de la literatura?

En Cuba se estimula bastante la lectura a través de las ferias del libro y de las presentaciones de los autores, pero padecemos de las mismas dificultades que presenta el planeta entero en cuanto a los cambios ocurridos con las revoluciones virtuales y tecnológicas a las que debemos adaptarnos. Mercado, publico que lee de modos diferentes a los anteriores públicos, escritores que se expresan diferente a los anteriores escritores, lectores distintos, en fin, que en Cuba existen los mismos retos que tienen el resto de los humanos, pero con la maldita circunstancia del agua por todas partes, al decir de un gran poeta, algo que nos aísla más si no actuamos con riesgos y energías creadoras.

\section{Soletras: ¿Cómo camina la recepción de sus libros, dentro y fuera de Cuba?}

Bueno, ahora mismo respondo estas preguntas sentado en una mesa de bar de un café de Zaragoza, España, después de haber recorrido territorios como Huelva, donde he obtenido el importante Premio Internacional de Relatos Cortos José Nogales, 2018, donde además presente mi novela La soledad del tiempo, además de recorrer pueblos españoles como Zafra, Ribera del Tiesto, Feria, Madrid, capital de España y por último, ya un poco agotado por tanta travesía terrenal, Zaragoza. Pero si soy sincero, más que premios en concursos literarios lo que más me interesa es que mi obra sea leída por lectores receptivos e inteligentes y que la crítica y la academia la estudien y de ello no puedo quejarme como escritor, pues se me estudia por parte de los académicos de varios sitios del mundo como Cuba, Brasil, Australia, EUA, Croacia y otros, se me ha traducido a varios idiomas y doy fe de que tengo lectores que me respetan bastante como escritor. Prefiero todo eso a los premios literarios.

Soletras: Hay una gran diversidad de autores y modos de narrar en América Latina. La autoficción es una marca de diversos autores actuales, como Alejandro Zambra, el peruano Jeremías Gamboa, la mexicana Valeria Luiselli, el cubano Carlos Manuel Álvarez, los brasileños Julián Fuks, Chico Buarque, entre otros, sólo para quedarse en algunos nombres. ¿Con su mirada de ficcionista, pero también de crítico de arte, ¿ a qué se debe esa demanda por la autoficción en la literatura latinoamericana?

Yo creo que se debe a que en estos tiempos ser escritor de ficciones es una tarea más fácil que en tempos anteriores. $\mathrm{O}$ sea, dedicarse a escribir ficciones personales parece más fácil. $\mathrm{O}$ sea, la presencia 


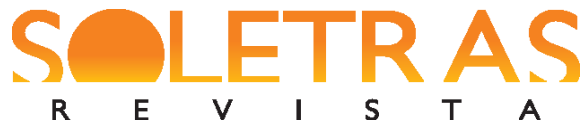

de las computadoras y de los cursos de escritura, y de los móviles y los portátiles inspiran, animan, condicionan que cualquier humano se lance a escribir desde su punto de vista cualquier historia. $\mathrm{O}$ sea, que existe esta tendencia, pero ella por sí sola no es garantía de calidad literaria entre quienes la apliquen, pues con la autoficción ocurre el mismo acero de rigor que con cualquier otra variante narrativa: esa obra tiene que tener calidad, o lo que es lo mismo, tiene que producir desasosiego en los lectores, tiene que entretener, tiene que ser profunda, filosófica, natural, arriesgada, novedosa, útil. Si no contiene alguno de esos ingredientes, pues el plató de la autoficción no tendrá el sabor que nuestro paladar esperaba y eso sería lamentable.

Soletras: En el cuento "Sax", de Com tato cubano, hay un recurso metalingüístico entrecortado por una mirada aguda en relación con la globalización. ¿Cómo ve el mundo globalizado y de qué manera busca reflejarlo en su narrativa?

En mi opinión el mundo está globalizado desde que Cristófaro Colombo pisó tierra americana, pero ocurre que ahora estamos más gracias a que las noticias entre las Europas, África, Asia y América no demoran lo mismo que en siglos anteriores. De eso trata "Sax", de dejar constancia en cuanto al intercambio de noticias y de estados de ánimos que en el cuento se entrecruzan como si se tratara de tomarse un vaso de agua después de almorzar, que es lo que ocurre hoy.

Soletras: En Com tato cubano, se reconocen voces narrativas autorreferenciales, cuyo contenido crítico no raramente indica problemas relacionados con la naturaleza de la literatura, los medios de comunicación y el lector. Hable un poco sobre su percepción acerca del papel del escritor latinoamericano en el mundo de hoy.

Nosotros, los escritores latino-americanos, tenemos un peso en las espaldas tremendo, porque debemos contar lo mejor que podamos sobre las alegrías, miserias, anhelos y sufrimientos de nuestros personajes, pueblos y países artificiales, que son los mismos del planeta, pero nos saben distintos cuando los aderezamos con samba, con tango, con bolero, y con las angustias de los pueblos de por acá. Y si todo esto se empaca en una narrativa que desafíe las tradiciones aunque las tenga en cuenta, entonces podría decir que vamos cumpliendo con nuestras responsabilidades como escritores de estos tiempos tan particulares que nos van tocando.

Soletras: La soledad del tiempo tuvo una excelente recepción crítica. ¿Cuál es la importancia de esta obra en su carrera?

La soledad del tiempo es mi única novela publicada, creo que ya eso la hace importante para mí. Espero que no sea mal recibida por los lectores de Brasil en caso de que algún día se logre publicar en idioma portugués. A mí me encantó escribirla y no le ha ido muy mal que digamos entre los lectores. La semana pasada recibí un correo de un joven escritor que me conmovió hasta la medula cuando me 


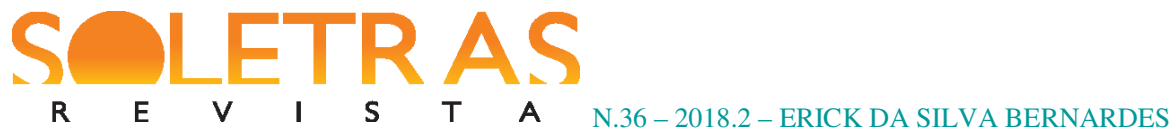

dijo que la novela le parecía genial. Eso recibido de un joven escritor es difícil de aceptar teniendo en cuenta que su deber es matarme en el mejor sentido.

Soletras: Se percibe que hay semejanzas entre los cuentos de Com tato cubano y su novela La soledad del tiempo. Hay fragmentos sobre racismo, críticas a los premios literarios, a los medios de comunicación. ¿El hecho de que esos asuntos polémicos en La soledad del tiempo" sean recurrentes en Com tato cubano tiene relación con su rol de escritor intelectual expresado en su ficción?

Sí, tiene usted mucha razón, recurro sin quererlo a un grupo de parámetros que me desasosiegan y preocupan para tratar de explicarme mi existencia. Creo que por eso escribo ficciones, para explicarme por qué estoy en este mundo y de esta manera.

Soletras: Cuando estaba en Brasil, lanzó su único libro en portugués, en la Facultad de Formación del Profesorado, de la Universidade do Estado do Río de Janeiro (UERJ-FFP). En uno de sus comentarios, dijo que se sentía en casa, debido a las similitudes entre las costumbres cubanas y brasileñas. Hable un poco de esa afinidad del escritor Alberto Guerra Naranjo con Brasil. ¿Puede establecer relaciones entre Cuba y Brasil en lo que se refiere a la literatura contemporánea?

Brasil y Cuba, Cuba y Brasil, son la misma cosa. Los nombres de los países y los países mismos son artificiales, inventos humanos en épocas de nombramientos ficticios, en épocas de modernidades. Pero a los pueblos no hay artificios que los divida, es por eso que me sentía a gusto con ustedes, no es que pareciera que estaba en casa, es que estaba en casa.

Soletras: Muchas gracias por la entrevista. Esperamos verlo pronto.

\section{Entrevista concedida em 28 de junho de 2018.}

